Fuzzy measure of secondary students' attitude towards Mathematics

Bhowmik, Monoranjan $\triangle$

Vidyasagar Teachers'Training College, India (mbvttc@gmail.com)

Banerjee, Bharati

Rabindra Bharati University, India (bharati_rbu@rediffmail.com)

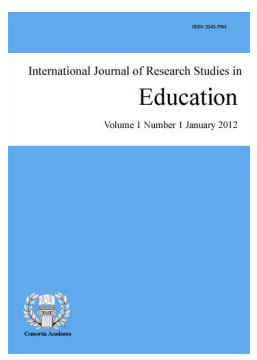

ISSN: 2243-7703 Online ISSN: 2243-7711

Received: 3 June 2012

\title{
Abstract
}

In this paper we proposed a fuzzy concept for measuring Likert type scale to measure students' attitude towards mathematics with an example of small sample. Students' attitude towards mathematics has been a factor that is known to influence students' achievement in mathematics. The purpose of this study is to find out the students attitude towards mathematics in a selected school of Midnapore (Rural). A total of 20 secondary students were administered with a questionnaire to find out their attitudes towards mathematics. The students answered questions regarding their personal confidence to mathematics and perceived usefulness of mathematics. The results show that the students' positive attitude towards mathematics is medium.

Keywords: learning style; fuzzy measure; attitude; mathematics; secondary students 


\section{Fuzzy measure of secondary students' attitude towards Mathematics}

\section{Introduction}

The knowledge of mathematics is an essential tool in our society (Baroody, 1987). It is a tool that can be used in our daily life to overcome the difficulties faced (Bishop, 1996). Due to this mathematics has been considered as one of the most important core subject in a school curriculum. More mathematics lessons are likely to be taught in schools and colleges throughout the world than any other subject (A. Orton, D. Orton, \& Frobisher, 2004). However, the standard tests and evaluations reveal that students do not perform to the expected level. The student under achievement in mathematics is not just a concern for particular countries, but has become a global concern over the years (Pisa, 2003).

Several studies and researches have been done in many countries to find the factors that influence the student's performance in mathematics. Among these factors, student's attitude towards mathematics is one important factor that has been consistently studied. Often, the studies on relationship between student's attitude and the students' academic performance show a positive relationship (Mohd, Mahmood, \& Ismail, 2011; Bramlett \& Herron, 2009; Nicolaidou \& Philippou, 2003; Papanastasiou, 2000; Ma \& Kishor, 1997). Hence students' attitude towards mathematics is a major factor that might influence the performance of the students. Due to this several studies has been conducted in different countries in order to find out the students attitude towards mathematics (Tahar, Ismail, Zamani, \& Adnan, 2010; Tezer \& Karasel, 2010; Maat \& Zakaria, 2010; Bramlett \& Herron, 2009; Tapia \& Marsh, 2004; Fennema \& Sherman, 1976).

The aim of this research is to find out the secondary students' attitude towards mathematics in a selected school of Midnapore district, West-Bengal, India. The research will focuses on finding the students' attitude towards mathematics using the fuzzy measurement.

\section{Literature Review}

Literature refers to attitude as a learned predisposition or tendency of an individual to respond positively or negatively to some object, situation, concept or another person. This positive or negative feeling is of moderate intensity and reasonable stability; sometimes it is especially resistant to change. In the variety of definitions of attitudes towards Mathematics (ATM) proposed in research studies, two main categories can be identified. Using a simple definition, ATM is just a positive or negative emotional disposition towards Mathematics (Mc Leod, 1994). Using a multidimensional definition, ATM comprises three components: an emotional respond to Mathematics, positive or negative, a conception about Mathematics, and a behavioral tendency with regard to Mathematics (Hart, 1989). Ma \& Kishor (1997) propose a wider definition; they conceive ATM as "an aggregated measure of a liking or disliking of Mathematics, a tendency to engage in or avoid mathematical activities, a belief that one is good or bad at Mathematics, and a belief that Mathematics is useful or useless" (p. 27).

Attitude is a central part of human identity. Everyday people love, hate, like, dislike, favor, oppose, agree, disagree, argue, persuade etc. All these are evaluative responses to an object. Hence attitudes can be defined as a summary evaluation of an object of thought (Bohner \& Wänke, 2002). They are inclinations and predispositions that guide an individuals' behavior (Rubinstein, 1986) and persuade to an action that can be evaluated as either positive or negative (Fishbein \& Ajzen, 1975). Attitudes develop and change with time (Rubinstein, 1986). According to multi component model of Attitude (Eagly \& Chaiken, 1993), attitudes are influenced by three components. They are cognitive (beliefs, thoughts, attributes), affective (feelings, emotions) and behavioral information (past events, experiences) (G. Maio, G. R. Maio, \& Haddock, 2010).

When reviewing literature on students' attitude towards mathematics, it reveals that several factors play a 
vital role in influencing students' attitude. These factors can be categorized into three distinctive groups. Firstly, factors associated with the students themselves. Some of these factors include students' mathematical achievement score (Köğce et al., 2009), anxiety towards mathematics, students self efficacy and self concept, extrinsic motivation (Tahar et al., 2010) and experiences at high school (Klein, 2004). Secondly, the factors that is associated with the school, teacher and teaching. Some of these factors that influence attitudes are teaching materials used by teacher, teachers' classroom management, teachers' content knowledge and personality, teaching topics with real life enriched examples, other students opinions about mathematics courses, teaching methods, reinforcement, receiving private tuition (Köğce et al., 2009), teachers' beliefs towards mathematics (Cater \& Norwood, 1997) and teachers" attitude toward mathematics (Ford 1994). Thirdly, factors from the home environment and society also affect students' attitude towards mathematics. Factors such as educational background of parents, occupation of parents (Köğce et al., 2009) and parental expectations play a crucial role in influencing students' attitude towards mathematics.

Due to these various factors students have different attitude towards mathematics. More often, the public image of mathematics is labeling it as a difficult, cold, abstract, theoretical and ultra rational subject (Ernest, 2004). However, some studies show that students have a relatively positive attitude towards mathematics (Tezer \& Karasel, 2010; Yilmaz et al., 2010). Sometimes, Mathematics is also considered as very important and largely masculine subject (Ernest, 2004). Several studies gives evidence that compared to boys, girls lack confidence in doing mathematical sums and viewed mathematics as a male domain (Meelissen \& Luyten, 2008; Odell \& Schumacher, 1998).

Costello (1991) reported that "almost all literature on this topic points to the commonly held perception that doing mathematics is consistent with a male self-image and inconsistent with a female self-image." This self image is usually caused by the peer pressure. Males are more inclined towards mathematics than females on being the male dominated domain. It is found that at secondary school level most of the girls don't actively participate in mathematics classes due to their poor perceptions about mathematics. Girls are negatively influenced by their sex-role stereotypes.

Poor mathematical skills in women deprived them from a large number of professions because in some countries mathematical background knowledge is the pre requisite for entrance in any profession. Sex differences are the serious concerns for the communities (Willis, 1995; Barnes \& Horne, 1996). In this era of science and technology, every field of life has been tremendously changed so it is necessary to compare the attitudes and achievements in mathematics on gender basis. It will support us for designing programs and strategies for participation of girls in mathematics at higher level. It's a common observation that at higher levels females take mathematics quite lesser than the male students. Ultimately the males fill more vacancies based on knowledge of mathematics than the females. Females do not prefer mathematics at higher level because they perceive it as a male domain. All professions requiring higher level knowledge of mathematics are dominated by male community. Many barriers are there for the female students to have their career in mathematics. Sometimes they feel pleasure in taking mathematics but their parents consider it as a useless effort for them, while, sometimes female students' show less confidence in mathematics than their male counterparts. Their attributions of failure and success also differ (Cohen \& Kosler, 1997; Dickens, \& Cornell, 1993).

Several measures and intervention programs has been designed for improving females attitude towards mathematics (American Association of University Women, 1992). Observations and researches indicate that "women are clustered in the life sciences with far fewer in physical sciences, mathematics, and engineering and computer science" (Gavin, 1997). Ainley and Fordham (Ainley \& Fordham, 1991) contributed for the excellence of school life and its relationship with other features. They investigated the student teacher relationship and concluded that student's satisfaction with school is not correlated with his academic success. This was concluded on the basis of the studies conducted on attitudes towards mathematics.

Teachers of mathematics tried to find out relationship of attitude with student's performance in mathematics 
during the last decade. They came to know that teaching learning process of mathematics depends upon the positive attitude towards mathematics. Serious efforts should be made to develop and gauge the positive attitude towards mathematics. Student's confidence is another ingredient for education of mathematics. "Having a positive attitude towards mathematics means generally enjoying working with mathematics and having confidence in one's own ability to do it but it does not mean that a student will display this positive attitude towards the whole area of mathematics all the time. Majority of the students love mathematics, but those who dropout due to mathematics; have a rather different viewpoint about it. It leads towards the fact that mathematics is a rough and tough subject. It is the attitude of the student which contributes a lot towards his perception about mathematics. It develops the adaptability and applicability in the learners (Booker, Briggs, Davey \& Nisbett, 1992; Schiefele \& Csikszentmihalyi, 1995). Students should be encouraged and prepared for accepting the challenges of day to day life (Mathematical Sciences Education Board and National Research Council, 1989). A study was needed to see the attitude of Indian students towards mathematics. This study will answer the possible questions regarding the attitude and achievement in mathematics.

\subsection{Fuzzy concept for measuring Likert type scale}

The most widely used scale among these is the Likert type attitude scale developed by Renis Likert (1932). The reason for its widespread use is that these scales are relatively easier to develop and administer compared to other scales. On the other hand, the disadvantage of Likert type scales is that, responses to different statements can generate the same aggregate scores. For instance, let's consider a Likert type attitude scale consisting of a number of sub dimensions. The scores for these sub dimensions could be varied: some could be low, while others could be high. Two students who have similar aggregate scores could have different sub-dimension scores. For example, let's say an attitude test has two dimensions A and B. A student could have a high score for sub-scale A and a low score for sub-scale B; and another student could have a low score for sub-scale A and a high score for sub-scale B.

When aggregate scores are considered, both students could be said to possess moderate attitudes. However, is it possible to claim that these two students have the same attitudes because they seem to have the same aggregate scores while their sub dimension scores are different? To what extent do sub dimensions scores explain the total aggregate scores? How can we formulate and calculate it mathematically? These kinds of questions might entail abstract concepts without clear limits. Rough sets approach could be used for this kind of evaluation of attitude scales. Vague concepts have preoccupied people's mind for centuries. Currently, the subject is very popular among computer engineers and mathematicians as well as philosophers and psychologists. Vague concepts are not easy to formulate using ordinary mathematical concepts since they may not include mathematically definite results. Thus, the necessity of alternative mathematical concepts is apparent for the mathematical modeling of vague concepts.

The idea of a vague or fuzzy concept is related to the Frege's (1904) boundary-line view. A concept is fuzzy if there are some objects which cannot be classified either to the concept or to its complements but are members of the concept's boundary. The first successful approach to fuzziness was the notion of a fuzzy set proposed by Lotfi Zadeh (1965). In this approach, sets are defined by partial membership in contrast to crisp membership used in classical definition of a set.

Where to apply: It occur in all the areas where human judgement, conclusion, and decision are important i.e. engineering, medicine, artificial intelligence, pattern recognition, meteorology, computer science, education, psychology, sociology etc.

Why fuzzy conception is so powerful: Fuzzy conception provides a means of representing non-random uncertainty. It is a marvellous tool of decision taking of the uncertainty associated with vagueness, with imprecision and lack of information regarding a particular respond of the subject. The under lying power of fuzzy conception can use in linguistic variables rather than quantitative variables to represent imprecise 
Fuzzy measure of secondary students' attitude towards Mathematics

measurement. It will mean different things depending on the application areas and the way of it measure. Because of its generality it can be well adopted in different circumstances and context.

Fuzzy measure: Fuzzy measure of decision means which we cannot measure precisely. Say for example, in Fennema-Sherman's scale of mathematics attitude scale one question "I am sure I can learn math", here subject opt his/her answer one out of four [strongly agree $(S A)$, agree $(A)$, disagree $(D)$, strongly disagree $(S D)$ with graded 4,3,2,1 accordingly]. But in real situation these linguistic terms [strongly-agree (SA), agree (A), disagree $(D)$, strongly-disagree $(S D)$ are vague/fuzzy terms (SA, A, D, SD) because against these terms no one can put preciously a particular value, these are the uncertainties. In this situation fuzzy measure is the most suitable measure for imprecise response.

Fuzzy measure means subject/person can assign a graded value calls it membership value or degree of belongingness or degree of believes which can take any value from the interval $[0,1]$.

Let, $\mathrm{X}=\left\{x_{1}=\right.$ strongly-disagree $(S D), \quad x_{2}=$ disagree $(D), \quad x_{3}=$ agree $(A), \quad x_{4}=$ strongly-agree $\left.(S A)\right\}$ and $\mu$ is called the membership value or degree of belongingness or degree of believes, where $\mu: X \rightarrow[0,1]$ for all $x \in X$. And the interval boundary of $\mathrm{X}$ is

\section{Table 1}

Fuzzy grading value

\begin{tabular}{ccccc}
\hline Group & $x_{1}=\mathrm{SD}$ & $x_{2}=\mathrm{D}$ & $x_{3}=\mathrm{A}$ & $x_{4}=\mathrm{SA}$ \\
\hline Interval & $0-2.5$ & $2.5-5$ & $5-7.5$ & $7.5-1$ \\
\hline
\end{tabular}

In this measure the subject/person are getting more freedom to assign his/her confidence value in any sub-division of decision. Table 2 shows the categorized value of the overall decision of the attitude towards mathematics based on the range of score.

Table 2

Categorized value

\begin{tabular}{ll}
\hline \multicolumn{1}{c}{ Mean Score } & \multicolumn{1}{c}{ Level } \\
\hline $0.00-0.33$ & Low \\
$0.34-0.66$ & Medium \\
$0.66-1.00$ & High \\
\hline
\end{tabular}

Note: In Fennema-Sherman's scale of mathematics attitude scale those questions which reflects positive attitude assign a positive value within the interval $[0,1]$ and for those questions which reflects negative attitude assign a negative sign in front of the corresponding value from the interval $[0,1]$.

Educational Implication: Fuzzy measure is very useful in the field educational psychological measurement. In our educational measurement every subject (individuals i.e. students or teacher) have to be answered some questioner or inventory with their perception or experience in grading system (Likert scale). But using fuzzy measure individuals can put their decision, perceptions or experiences in terms of numerical value within the interval [0.1]. So in fuzzy measure there is no need of further conversion of grading to numerical value by the manuals of the inventory. The main advantage in this measure is subject as a decision maker can put his/her decision in more precise value than grading.

Significant of the study: Since there are so many research in educational psychological measurement (anxiety, attitude, aptitude etc.) using the grading system. In our study we want to introduce a new type of measure called fuzzy measure. In this paper we proposed a fuzzy concept for measuring Likert type scale to measure students' attitude towards mathematics with an example of small sample 


\subsection{Research objective}

The main objective of this study is to determine the students' attitude towards mathematics.

\section{Methodology}

This is a quantitative study which explores secondary student's attitude towards mathematics in a selected secondary school of Midnapore (Rural). Population under consideration is from a secondary of Midnapore (Rural). The school has a population of 95 secondary students. A sample size of 20 students was determined using a sample size calculator from internet (www.surveysystem.com). Attitudes cannot be directly observed, so to measure attitudes one can simply ask the person or use indirect methods of inferring cues to measure implicit attitudes. The scale used in this study is, one of the most popular scales used over the past three decades, Fennema-Sherman Mathematics attitude scale (Tapia \& Marsh, 2004; Kloosterman \& Stage, 1992).

Here we use the fuzzy measure of the Fennema-Sherman Mathematics attitude scale. However for the convenience of this study two instruments were used. They are personal confidence of the students to do mathematics and usefulness of mathematics as perceived by the students. The questionnaire used is adapted from "A Modified Fennema-Sherman Mathematics Attitude scale". The response rate from the respondents was $100 \%$ and the data collected were analyzed using Statistical Package for Social Science (SPSS).

\section{Results and Discussion}

This section is divided into three parts, demographic characteristics and student's attitude towards mathematics.

\subsection{Demographic characteristics}

The number of students participated (20) in this study from a selected school of Midnapore District a rural area of West-Bengal, India.

\subsection{Attitude towards Mathematics}

The questionnaire was analyzed to find out the students attitude towards mathematics (personal confidence of students and perceived usefulness of mathematics). Table 3 shows the grading score of a particular Student $\left(S_{1}\right)$. It reflects, how to calculate the total grade or fuzzy value of the personal confidence of mathematics $\mu_{T}(c)\left[\mu\left(c^{+}\right)\right.$and $\mu\left(c^{-}\right)$are the positive and negative direction of the questioner] and perceived usefulness of mathematics $\mu_{T}(u)\left[\mu\left(u^{+}\right)\right.$and $\mu\left(u^{-}\right)$are the positive and negative direction of the questioner]. Where $\mu_{T}(c)$ and $\mu_{T}(u)$ can be calculated by the following equations.

$$
\begin{aligned}
& \mu_{T}(c)=\frac{\mu\left(c^{+}\right)+\left\{1-\left|\mu\left(c^{-}\right)\right|\right\}}{2} \ldots \ldots \ldots \ldots \ldots(1) \\
& \mu_{T}(c)=\frac{\mu\left(c^{+}\right)+\left\{1-\left|\mu\left(c^{-}\right)\right|\right\}}{2} \ldots \ldots \ldots \ldots(2)
\end{aligned}
$$

Table 4 represents the statistical table of the whole students of the sample studied. Where $\mu_{T}(c)$ and $\mu_{T}(u)$ can be calculated by the equations (1) and (2). 
Table 3

Fuzzy value decision of a student

\begin{tabular}{cccc}
\hline \multicolumn{4}{c}{ Student $\left(S_{1}\right)$} \\
Confidence (c) & \multicolumn{2}{c}{ Usefulness (u) } \\
\hline$\mu\left(c^{+}\right)$ & $\mu\left(c^{-}\right)$ & $\mu\left(u^{+}\right)$ & $\mu\left(u^{-}\right)$ \\
& & & -0.8 \\
0.6 & -0.5 & 0.6 & -0.7 \\
0.3 & -0.4 & 0.9 & -0.3 \\
0.7 & -0.8 & 0.5 & -0.1 \\
0.4 & -0.3 & 0.8 & -0.5 \\
0.5 & -0.4 & 0.3 & -0.4 \\
0.9 & -0.2 & 0.1 & Mean $=-0.47$ \\
Mean=0.56 & Mean=-0.45 & Mean=0.53
\end{tabular}

Table 4

Statistical data of the participants

\begin{tabular}{|c|c|c|c|c|c|c|}
\hline \multirow{2}{*}{ Students } & \multicolumn{3}{|c|}{ Confidence } & \multicolumn{3}{|c|}{ Usefulness } \\
\hline & $\mu\left(c^{+}\right)$ & $\mu\left(c^{-}\right)$ & $\mu_{T}(c)$ & $\mu\left(u^{+}\right)$ & $\mu\left(u^{-}\right)$ & $\mu_{T}(u)$ \\
\hline$S_{1}$ & 0.56 & -0.45 & 0.55 & 0.57 & -0.67 & 0.45 \\
\hline$S_{2}$ & 0.74 & -0.25 & 0.74 & 0.35 & -0.35 & 0.50 \\
\hline$S_{3}$ & 0.83 & -0.35 & 0.74 & 0.48 & -0.45 & 0.51 \\
\hline$S_{4}$ & 0.44 & -0.44 & 0.50 & 0.75 & -0.30 & 0.72 \\
\hline$S_{5}$ & 0.86 & -0.53 & 0.66 & 0.80 & -0.43 & 0.68 \\
\hline$S_{6}$ & 0.51 & -0.60 & 0.45 & 0.54 & -0.60 & 0.47 \\
\hline$S_{7}$ & 0.60 & -0.58 & 0.51 & 0.65 & -0.40 & 0.62 \\
\hline$S_{8}$ & 0.41 & -0.44 & 0.48 & 0.61 & -0.35 & 0.63 \\
\hline$S_{9}$ & 0.70 & -0.70 & 0.50 & 0.65 & -0.25 & 0.70 \\
\hline$S_{10}$ & 0.65 & -0.52 & 0.56 & 0.59 & -0.55 & 0.52 \\
\hline$S_{11}$ & 0.75 & -0.58 & 0.58 & 0.70 & -0.55 & 0.57 \\
\hline$S_{12}$ & 0.85 & -0.53 & 0.66 & 0.85 & -0.55 & 0.65 \\
\hline$S_{13}$ & 0.45 & -0.25 & 0.60 & 0.85 & -0.65 & 0.60 \\
\hline$S_{14}$ & 0.38 & -0.54 & 0.42 & 0.50 & -0.50 & 0.50 \\
\hline$S_{15}$ & 0.54 & -0.34 & 0.60 & 0.75 & -0.48 & 0.63 \\
\hline$S_{16}$ & 0.65 & -0.66 & 0.49 & 0.60 & -0.65 & 0.47 \\
\hline$S_{17}$ & 0.69 & -0.45 & 0.62 & 0.49 & -0.45 & 0.52 \\
\hline$S_{18}$ & 0.70 & -0.55 & 0.57 & 0.58 & -0.65 & 0.46 \\
\hline$S_{19}$ & 0.85 & -0.56 & 0.64 & 0.80 & -0.76 & 0.52 \\
\hline$S_{20}$ & 0.55 & -0.38 & 0.58 & 0.65 & -0.48 & 0.58 \\
\hline
\end{tabular}

Table 5 shows the personal confidence of mathematics; perceived usefulness of mathematics and overall attitude towards mathematics is medium. 
Bhowmik, M. \& Banerjee, B.

\section{Table 5}

Participants' attitudes towards mathematics

\begin{tabular}{lllc}
\hline \multicolumn{1}{c}{ Variable } & Mean & Standard Deviation & level \\
\hline Personal Confidence & 0.57 & 0.0971 & Medium \\
Usefulness of Mathematics & 0.56 & 0.0801 & Medium \\
Overall Performance & 0.565 & 0.088 & Medium \\
\hline
\end{tabular}

\section{Conclusion}

As a conclusion to this research it can be said that, since the student's positive attitude towards mathematics is at medium level, it shows that there are still possible room for improvement. However, it is interesting to know that despite the lower performance of Midnapore (Rural) students in mathematics, the attitude of the respondents of this study is fairly positive.

\subsection{Recommendation}

It is highly recommended that the maximum effort should be given to improve the student's attitude towards mathematics and conduct further studies to find factors influencing student's attitude towards mathematics. Moreover studies could be conducted to find if there is a relationship between student's attitude and performance of students in the schools of Midnapore (Rural) and also can be used to conduct the difference of attitude towards mathematics among the girls' and boys'. This fuzzy measure can be used in a large sample to make general conclusion of a population. In the next paper the researchers are trying to use intuitionistic fuzzy measure i.e. for value and against value to each question to each individual so that the degree of entropy or degree of hesitation can be estimated.

\section{References:}

Ainley, J., \& Fordham, A. (1991). The development and application of national indicators of Educational effectiveness. In J. Hewton (Ed.), Performance indicators in education: What can they tell us? (pp. 103-116). Brisbane: Department of Education, Queensland.

American Association of University Women (1992). Short changing girls, short-changing America: A call to action. ERIC Document Reproduction Service No. ED 340658.

Baroody, A. J. (1987). Children's Mathematical thinking: developmental framework for preschool, primary, and special education teachers. New York: Teachers college press.

Barnes, M., \& Horne, M. (1996). Gender and mathematic. Research in Mathematics Education in Australasia 1992-1995. Mathematics Education Research Group of Australasia.

Bishop, A. J. (1996). International handbook of mathematics education. Springer.

Bohner, G., \& Wänke, M. (2002). Attitudes and attitude change. Psychology Press.

Boswell, S. (1979). Nice girls don't study mathematics: The perspective from elementary school. Symposium paper presented at the annual meeting of the American Educational Research Association, San Francisco.

Booker, G., Briggs, J., Davey, G., \& Nisbett, S. (1992). Teaching primary mathematics. Melbourne: Longman Cheshire.

Bramlett, D. C., \& Herron, S. (2009). A study of African-American college students' attitude towards mathematics. Journal of Mathematical Sciences \& Mathematics Education, 4(2), 43-51.

Cater, G. S., \& Norwood, K. S. (1997). The relationship between teacher and students, belief about mathematics. School science and mathematics, 97(2), 62-67. <http://dx.doi.org/10.1111/j.1949-8594.1997.tb17344.x>

Cohen, R., \& Kosler, J. (1991). Gender equity in high school math: A study of female participation and achievement. ERIC Document Reproduction Service No. 345935. 
Costello, J. (1991). Teaching and learning mathematics (pp. 11-16). London: Routledge.

Dickens, M. N., \& Cornell, D. G. (1993). Parental influences on the mathematics self-concept of high ability adolescent girls. Journal for the Education of the Gifted, 17, 53-73. <http://dx.doi.org/10.1177/016235329301700106>

Eagly, \& Chaiken, J. (1993). The psychology of attitudes, Fort Worth, NY: Harcourt Brace Jovanovich.

Ernest, P. (2004). Images of mathematics, values and gender. In S. Johnston-Wilder \& B. Allen (Eds.), Mathematics education: Exploring the culture of learning. Routledge.

Ethington, C. A. (1992), Gender differences in a psychological model of mathematics achievement. Journal for Research in Mathematics Education, 23(2), pp. 166-181. <http://dx.doi.org/10.2307/749499>

Fennema, E., \& Sherman, J. A. (1976). Fenemma-Sherman Mathematics Attitude Scales: Instruments designed to measure attitudes towards the learning of mathematics by females and males. Journal for research in Mathematics Education, 7(5), 324-326. <http://dx.doi.org/10.2307/748467>

Fishbein, M., \& Ajzen, I. (1975). Belief, attitude, intention and behavior: An introduction to theory and research. Reading, MA: Addison - Wesley.

Ford, M. I. (1994). Teachers' beliefs about mathematical problem solving in the elementary school. School Science and Mathematics, 94(6), 314-322. <http://dx.doi.org/10.1111/j.1949-8594.1994.tb15683.x>

Frege, G. (1904). Grundgesetze Arithmentik (Basic principles of arithmetic). In P. T. Geach \& M. Black (Eds.), Selections from the philosophical writings of Gotlob Frege. Oxford: Blackwell.

Gavin, M. K. (1997). A gender study of students with high mathematics ability: Personological, educational and parental influences on the intent to pursue quantitative fields of study in college. Retrieved 26 February 2007 from http://www.gifted.uconn.edu/nrcgt/newsletter/spring97/sprng974.html

Hart, L. (1989). Describing the affective domain: Saying what we mean. In D. B. McLeod \& V. M. Adams (Eds.), Affect and mathematical problem-solving: A new perspective (pp. 37-45). New York: Springer-Verlag. <http://dx.doi.org/10.1007/978-1-4612-3614-6_3>

Klein, M. (2004). The premise and promise of inquiry based mathematics in pre-service teacher education: A poststructuralist analysis. Asia-Pacific Journal of Teacher Education, 32(1), 35-47. <http://dx.doi.org/10.1080/1359866042000206008>

Köğce, D., Yıldız, C., Aydın, M., \& Altındağ, R. (2009). Examining elementary school students' attitudes towards mathematics in terms of some variables. Proceedia Social and Behavioral Sciences, 1(1), 291-295. <http://dx.doi.org/10.1016/j.sbspro.2009.01.053>

Likert, R. (1932). A technique for the measurement of attitudes archives of psychology (p. 140).

Ma, X., \& Kishor, N. (1997). Assessing the relationship between attitude toward mathematics and achievement in mathematics: A meta-analysis. Journal for Research in Mathematics Education, 28(1), 27-47. <http://dx.doi.org/10.2307/749662>

Maat, S. M. B., \& Zakaria, E. (2010). The learning environment, teacher's factor and students' attitude towards mathematics amongst engineering technology students. International Journal of Academic Research, 2(2), 16-20

Mathematical Sciences Education Board and National Research Council. (1989). Everybody counts: A report to the nation on the future of mathematics education. Washington: National Academy Press.

McLeod, B. D. (1994). Research on affect and mathematics learning in the JRME: 1970 to the present. Journal for Research in Mathematics Education, 25(6), 637-647. <http://dx.doi.org/10.2307/749576>

Maio, G., Maio, G. R., \& Haddock, G. (2010). The psychology of attitudes and attitude change. SAGE Publications Ltd.

Meelissen, M., \& Luyten, H. (2008). The Dutch gender gap in mathematics: Small for achievement, substantial for beliefs and attitudes. Studies in Educational Evaluation, 34, 82-93. $<$ http://dx.doi.org/10.1016/j.stueduc.2008.04.004>

Mohd, N., Mahmood, T. F. P. T., \& Ismail, M. N. (2011). Factors that influence students in mathematics achievement. International Journal of Academic Research, 3(3), 49-54.

Nicolaidou, M., \& Philippou, G. (2003). Attitudes towards mathematics, self-efficacy and achievement in problem solving. European Research in Mathematics III. 
Bhowmik, M. \& Banerjee, B.

Odell, P. M. \& Schumacher, P. (1998). Attitudes towards mathematics and predictors of college mathematics grades: gender difference in a 4-year business college. Journal of Education for Business, 74(1), 34-38. $<$ http://dx.doi.org/10.1080/08832329809601658>

Orton, A., Orton, D., \& Frobisher, L. J. (2004). Insights into teaching mathematics. Continuum International Publishing Group.

Papanastasiou, C. (2000). Effects of attitudes and beliefs on mathematics achievement. Studies in Educational Evaluation, 26, 27-42. <http://dx.doi.org/10.1016/S0191-491X(00)00004-3>

PISA (2003). OECD programme for International Student Assessment (PISA). Retrieved on 29 June 2011 from http://www.pisa.oecd.org/

Rubinstein, M. F. (1986). Tools for thinking and problem solving. New Jersey: Prentice Hall.

Schiefele, U., \& Csikszentmihalyi, M. (1995). Motivation and ability as factors in mathematics experience and achievement. Journal for research in mathematics education, 26(2), 163-181. $<$ http://dx.doi.org/10.2307/749208>

Sherman, J. A. (1982), Mathematics the critical filter: A look at some residues. Psychology of Women Quarterly, 6(4), 428-444. <http://dx.doi.org/10.1111/j.1471-6402.1982.tb01071.x>

Tahar, N. F., Ismail, Z., Zamani, N. D., \& Adnan, N. (2010). Students' attitude toward mathematics: The use of factor analysis in determining the criteria. Proceedia-Social and Behavioral Sciences, 8, 476-481. $<$ http://dx.doi.org/10.1016/j.sbspro.2010.12.065>

Tapia, M., \& Marsh II, G. E. (2004). An instrument to measure mathematics attitudes. Academic Exchange Quarterly, 8(2), 130-143.

Tezer, M., \& Karasel, N. (2010). Attitudes of primary school 2nd and 3rd grade students towards mathematics course. Proceedia Social and Behavioral Sciences, 2, 5808-5812. $<$ http://dx.doi.org/10.1016/j.sbspro.2010.03.947>

Willis, S. (1995). Gender justice and the mathematics curriculum: Four perspectives. In: L. Parker, L. Rennie, \& B. Fraser (Eds.), Gender, science and mathematics shortening the shadow (pp. 41-51). Dordecht: Kluwer.

Yilmaz, C., Altun, S. A., \& Ollkun, S. (2010). Factors affecting students' attitude towards math: ABC theory and its reflection on practice. Proceedia Social Science and Behavioral Sciences, 2, 4502-4506. $<$ http://dx.doi.org/10.1016/j.sbspro.2010.03.720>

Zadeh, L.A. (1965). Fuzzy sets. Information Control, 8, 338-353. $<$ http://dx.doi.org/10.1016/S0019-9958(65)90241-X> 